Detonation Reaction Zones in Condensed Explosives

Craig M. Tarver

July 18, 2005

14th APS Topical Conference on SCCM

Baltimore, MD, United States

July 31, 2005 through August 5, 2005 
This document was prepared as an account of work sponsored by an agency of the United States Government. Neither the United States Government nor the University of California nor any of their employees, makes any warranty, express or implied, or assumes any legal liability or responsibility for the accuracy, completeness, or usefulness of any information, apparatus, product, or process disclosed, or represents that its use would not infringe privately owned rights. Reference herein to any specific commercial product, process, or service by trade name, trademark, manufacturer, or otherwise, does not necessarily constitute or imply its endorsement, recommendation, or favoring by the United States Government or the University of California. The views and opinions of authors expressed herein do not necessarily state or reflect those of the United States Government or the University of California, and shall not be used for advertising or product endorsement purposes. 


\title{
DETONATION REACTION ZONES IN CONDENSED EXPLOSIVES
}

\author{
Craig M. Tarver \\ Lawrence Livermore National Laboratory \\ P.O. Box 808, L-282, Livermore, CA 94551
}

\begin{abstract}
Experimental measurements using nanosecond time resolved embedded gauges and laser interferometric techniques, combined with Non-Equilibrium Zeldovich - von Neumann - Doring (NEZND) theory and Ignition and Growth reactive flow hydrodynamic modeling, have revealed the average pressure/particle velocity states attained in reaction zones of self-sustaining detonation waves in several solid and liquid explosives. The time durations of these reaction zone processes is discussed for explosives based on pentaerythritol tetranitrate (PETN), nitromethane, octahydro-1,3,5,7-tetranitro-1,3,5,7-tetrazocine (HMX), triaminitrinitrobenzene(TATB) and trinitrotoluene (TNT).
\end{abstract}

\section{INTRODUCTION}

It is essential to know the pressure/particle velocity history in the reaction zone of a detonating condensed phase explosive to determine the momentum produced in surrounding materials. The Non-Equilibrium Zeldovich - von Neumann Doring (NEZND) theory was developed to identify the non-equilibrium chemical processes that precede and follow exothermic chemical energy release within the reaction zones of self-sustaining detonation waves in gaseous, liquid and solid explosives (1-10). Prior to the development of the NEZND model, the chemical energy released was merely treated as a heat of reaction in the conservation of energy equation in the ChapmanJouguet (C-J) (11,12), Zeldovich - von NeumannDoring (ZND) (13-15), and curved detonation wave front theories (16). NEZND theory has explained many experimentally determined detonation wave properties including: the induction time delays for the onset of chemical reaction; the rapid rates of the chain reactions that form the reaction product molecules; the de-excitation rates of the initially highly vibrationally excited products; the feedback mechanism that allows the chemical energy to sustain the leading shock wave front at an overall constant detonation velocity; and the establishment of the three-dimensional Mach stem structure of the leading shock wave front common to all detonations.
Along with a physical understanding of the processes that occur within the reaction zone of a detonation wave, it is also necessary to have a practical reactive flow model that can be used to predict shock initiation and detonation wave propagation in one-, two-, and three-dimensional hydrodynamic computer codes. The Ignition and Growth model (17) has been very successful in this regard. It was formulated using compression and pressure dependent reaction rate laws and calibrated to available experimental data. Nanosecond time resolved data has been obtained using: embedded pressure gauges (18); embedded particle velocity gauges (19); electrical conductivity probes (20); and laser interferometric techniques, such as VISAR (21) and Fabry-Perot (22), to measure free surface velocities and interface particle velocities. The average detonation wave reaction zone profiles for nitromethane, PETN, HMX, TATB and TNT have been determined and are discussed in this paper.

\section{NEZND THEORY OF DETONATION}

Figure 1 illustrates the various processes that occur in the NEZND model of detonation in condensed explosives. At the head of every detonation wave is a three-dimensional Mach stem shock wave front. Behind the leading shock front in solid and liquid explosives, the phonon modes are first excited, followed by multi-phonon excitation of 
the lowest frequency vibrational (doorway) modes and then excitation of the higher frequency modes by multi-phonon up-pumping and internal vibrational energy redistribution (IVR)(23). Internal energy equilibration is being studied in shocked liquid and solid explosives by Dlott et al. (24) and Fayer et al. (25). Only after the explosive molecules become vibrationally excited can chemical reactions begin. Recently McGrane et al. (26) showed using laser shock generation methods that induction times of tens of picoseconds were required for the dissociation of nitro groups in poly (vinyl nitrate) films.

The induction time for the initial endothermic bond breaking reaction can be calculated using high pressure - high temperature transition state theory. The reaction rate constant $\mathrm{K}$ is given by:

$$
\mathrm{K}=(\mathrm{kT} / \mathrm{h}) \mathrm{e}^{-\mathrm{s}} \sum_{\mathrm{i}=0}^{\mathrm{s}-1}(\mathrm{E} / \mathrm{RT})^{\mathrm{i}} \mathrm{e}^{-\mathrm{E} / \mathrm{RT} / \mathrm{i} !}
$$

where $\mathrm{A}$ is the pre-exponential factor, $\mathrm{E}$ is the activation energy, k, h, and R are Boltzmann's, Planck's, and the gas constant, respectively, and $\mathrm{s}$ is the number of neighboring vibrational modes interacting with the transition state. Reasonable induction reaction rate constants have been calculated for detonating solids and liquids using Eq. (1) with realistic equations of state and values of s (10).

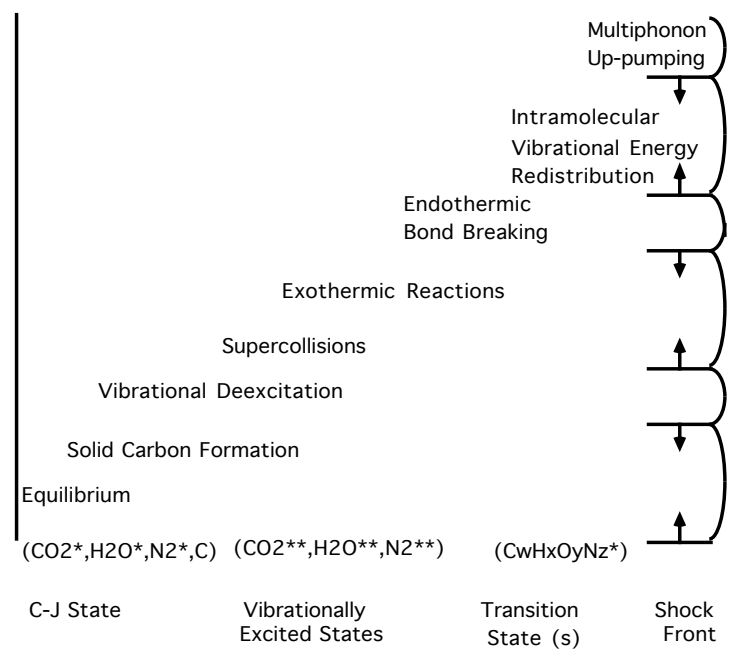

FIGURE 1. The Non-Equilibrium Zeldovich - von Neumann-Doring (NEZND) model of detonation for condensed phase explosives
Following the induction and endothermic initial bond breaking processes, exothermic chain reactions follow in which reaction product gases are formed in highly vibrationally excited states (2). These excited products either undergo reactive collisions with surrounding explosive molecules or non-reactive collisions with their neighbors. Some non-reactive collisions are "super-collisions"(27) in which transfer several quanta of vibrational energy. Since reaction rates increase rapidly with each quanta of vibrational energy available, reactive collisions dominate and the main chemical reactions are extremely fast. Once the chain reactions are completed, the rest of the reaction zone is dominated by vibrational de-excitation of the gaseous product molecules and solid carbon formation. These processes control the average length of the reaction zone and the approach to the equilibrium C-J state. The relative lengths of these major time dependent processes determine the average pressure - time profile of each detonation zone discussed below.

\section{PETN DETONATION REACTION ZONES}

In a Fabry-Perot study of PETN detonation, Tarver et al. (28) found that all of the experimental data could be accurately calculated using a C-J model of the PETN detonation wave. Since the Fabry-Perot system used in that study had a five to ten nanosecond time resolution, this implied that the total reaction zone length in detonating PETN was less than $10 \mathrm{~ns}$. PETN is well-oxidized and forms little or no solid carbon in its reaction products (20). Thus the formation and vibrational de-excitation of its gaseous products can proceed very rapidly without the interference of collisions with developing carbon clusters. The calculated induction time for the initial PETN decomposition reaction is a few tenths of a nanosecond (10), which is close to the experimental induction times for "super" detonation observed in PETN pressed nearly to theoretical maximum density (TMD) (28). Thus determination of the PETN detonation reaction zone profile requires the use of subnanosecond techniques, such as new VISAR's, that are becoming available (29).

\section{NITROMETHANE REACTION ZONES}

The liquid nitromethane detonation reaction zone has been studied by several techniques with the most recent and fastest time resolution being the "home made"VISAR studies of Sheffield et al. (29). 
Sheffield et al. measured a von Neumann spike state of approximately $20 \mathrm{GPa}$ that lasted for $1-3 \mathrm{~ns}$, in good agreement with calculated estimates $(4,10)$. A rapid decrease in particle velocity was then measured which lasted for about $7 \mathrm{~ns}$, followed by a slower decrease that lasted for approximately $50 \mathrm{~ns}$. These particle velocity results correlate well with the electrical conductivity probe measurements of Hayes (20) that show that carbon formation begins $1 \mathrm{~ns}$ or so behind the detonation wave front and increases to a maximum at about $5 \mathrm{~ns}$, which lasts for at least 20 ns. Thus the nitromethane detonation wave profile appears to show an induction time of $1-3 \mathrm{~ns}$, rapid exothermic reaction for perhaps $7 \mathrm{~ns}$, and product equilibration and solid carbon formation that lasts another $20-50 \mathrm{~ns}$. The exact location of the C-J state at which the reaction zone ends and the rarefaction wave begins can not yet be determined, because the slope differences in particle velocity or pressure values near the C-J state are very small.

\section{HMX DETONATION REACTION ZONES}

It has long been known that the main chemical energy release in detonating HMX-based explosives must occur within $20 \mathrm{~ns}$ to explain their detonation velocity versus charge diameter data (30). More recent VISAR measurements of Gustavsen et al. (31) on detonating PBX 9501 (95\% HMS, 2.5\% BDNPA/F and $2.5 \%$ Estane) show a rapid decrease in particle velocity for about $20 \mathrm{~ns}$ followed by a slower rate of decrease for several tens of ns. The measured peak pressure of approximately $40 \mathrm{GPa}$ agrees well with theoretical predictions and the unreacted equation of state in the Ignition and Growth model, which was calibrated to embedded gauge and Fabry-Perot data. Figure 2 shows the experimental detonation velocity versus inverse cylindrical charge radius data (32) for PBX 9404 (94\% HMX, 3\% nitrocellulose, and 3\% chloro ethyl phosphate) compared to Ignition and Growth reactive flow calculations which assume that $90 \%$ of the chemical energy is released within 20 ns followed by the remaining $10 \%$ being released in 80 more ns. Thus it appears that the main energy release and vibrational equilibration in detonating HMX takes about $20 \mathrm{~ns}$ and that solid carbon cluster formation is not complete for another $60-80 \mathrm{~ns}$.

\section{TATB DETONATION REACTION ZONES}

TATB-based explosive are oxygen poor and thus

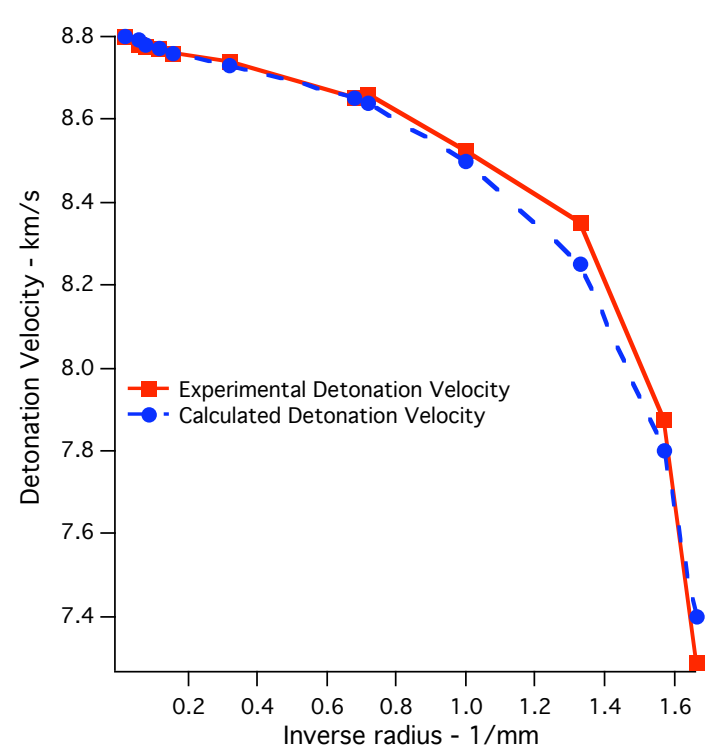

FIGURE 2. Experimental and calculated detonation velocity versus inverse radius curves for PBX 9404

produce a great deal of solid carbon in their detonation products. The main energy release occurs over approximately $60-80 \mathrm{~ns}$ and the overall reaction zone length is about $2.5-3 \mathrm{~mm}$ or $300-$ 400 ns. Several embedded gauge and laser interfeometry studies have shown these general features (33). Ignition and Growth modeling of LX17 (92.5\% TATB and 7.5\% Kel-F) and PBX 9502 (95\% TATB and $5 \%$ Kel-F) detonation has accurately calculated a great deal of one-, two- and three-dimensional experimental using a $80 \%$ energy release over the first $60 \mathrm{~ns}$ followed the remaining $20 \%$ released over another 240 ns $(34,35)$. The experimentally measured von Neumann spike state for LX-17 is $33.5 \mathrm{GPa}$, which agrees closely with extrapolated unreacted shock Hugoniot data and the assumed unreacted equation of state used in the Ignition and Growth model. As for other explosives, the C-J state is not readily apparent from the experimental records, but a C-J pressure of $27 \mathrm{GPa}$ for LX-17 can be used to predict all of the existing detonation and overdriven data.

\section{TNT DETONATION REACTION ZONES}

Like TATB, TNT is under oxidized and produces a great of solid carbon. Kury et al. (36) modeled laser interferometric data on detonating and overdriven TNT using a von Neumann spike pressure of 25 
GPa, a fast reaction of $90 \%$ of the TNT in $80 \mathrm{~ns}$, a slow reaction of the remaining $10 \%$ in another 200 $\mathrm{ns}$, and a C-J pressure of $19 \mathrm{GPa}$. Electrical conductivity measurements in TNT (20) showed that the conductivity increased for over $100 \mathrm{~ns}$ behind the shock front. Thus the detonation reaction zone profile of TNT is similar to that of TATB, but the lower initial density of TNT causes lower pressures.

\section{DISCUSSION}

Average detonation reaction zone profiles have been measured by several ns resolution techniques and calculated using the Ignition and Growth reactive flow model. Experimental resolution of the three dimensional shock front structure of solid explosive detonation waves is becoming practical (37). Temperature measurements within the detonation reaction zone are required to build more complete reactive flow models based on Arrhenius kinetics.

\section{ACKNOWLEDGMENTS}

This work was performed under the auspices of the U.S. Department of Energy by the University of California, Lawrence Livermore National Laboratory under Contract No.W-7405-ENG-48.

\section{REFERENCES}

1. Tarver, C. M., "On the Chemical Energy Release in Self-Sustaining Detonation Waves in Gaseous and Condensed Explosives," Ph. D. thesis, The Johns Hopkins University, Baltimore, MD, 1973

2. Tarver, C. M. Comb. Flame 46, 111-133 (1982).

3. Tarver, C. M., Comb. Flame 46, 135-155 (1982).

4. Tarver, C. M., Comb. Flame 46, 157-179 (1982).

5. Tarver, C. M., Fried, L. E., Ruggerio, A. J., and Calef, D. F., Tenth International Detonation Symposium, Office of Naval Research ONR 3339512, Boston, MA, 1993, p. 3-11.

6. Tarver, C. M., in Shock Compression of Condensed Matter-1997, S. C. Schmidt, D. P. Dandekar, and J. W. Forbes, eds., AIP Press, 1998, pp. 301-304.

7. Tarver, C. M., J. Phys. Chem. A 101, 4845-4851 (1997).

8. Tarver, C. M., in Shock Compression of Condensed Matter - 1999, M. D. Furnish, L. C. Chhabildas, and R. S. Hixson, eds., AIP Press, 2000, pp. 873877.

9. Tarver, C. M., in Shock Compression of Condensed Matter - 2001, N. Thadhani, Y. Horie, and M. Furnish, eds., AIP Press, pp. 42-49.

10. Tarver, C. M.. "What is a Shock Wave to an Explosive Molecule?" in "High Pressure Shock Compression of Solids VI?" Y. Horie, L. Davison, and N. N. Thadhani, ed., Springer-Verlug, New York, 2003, pp. 323-340.

11. Chapman, D. L., Phil. Mag. 213, Series 5, 47, 90 (1899).

12. Jouguet, E., J. Pure Appl. Math. 70, Series 6, 1,
347 (1904).

13. Zeldovich, Y. B., J. Exper. Theor. Phys. (USSR) 10, 542 (1940).

14. Von Neumann, J., Office of Science Research and Development, Report No. 549 (1942).

15. Doring, W., Am. Physik 43, 421 (1943).

16. Wood, W. W. and Kirkwood, J. G., J. Chem. Phys. 29, 957 (1958).

17. Tarver, C. M., Hallquist, J., and Erickson, L. M., Eighth Symposium (International) on Detonation, Naval Surface Weapons Center NSWC MP86-194, Albuquerque, NM, 1985, pp. 951-961.

18. Tarver, C. M., Parker, N. L., Palmer, H. G., Hayes, B. and Erickson, L. M., J. Energetic Materials 1, 213-250 (1983).

19. Hayes, B. and Tarver, C. M., Seventh Symposium (International) on Detonation, Naval Surface Weapons Center NSWC 82-334, Annapolis, MD, 1981, pp. 1029-1039.

20. Hayes, B., Fourth Symposium (International) on Detonation, Office of Naval Research ACR-126, White Oak, MD, 1965, pp. 595-601.

21. Sheffield, S. A., Bloomquist, D. D., and Tarver, C. M., J. Chem. Phys. 80, 3831-3844 (1984).

22. Tarver, C. M., Tao, W. C., and Lee, C. G., Propellants, Explosives, Pyrotechnics 21, 238246 (1996).

23. Weston, Jr., R. E. and Flynn, G. W. Ann. Rev. Phys. Chem. 43, 559-592 (1993).

24. Hong, X., Chen, S., and Dlott, D. D., J. Phys. Chem. 99, 9102-9109 (1995).

25. Holmes, W., Francis, R. S., and Fayer, M. D., J. Chem. Phys. 110, 3576-3583 (1999).

26. McGrane, S.D., Moore, D. S., and Funk. D. J., J. Phys. Chem. A 108, 9342-9347 (2004)

27. Bernshtein, V. and Oref, I., J. Phys. Chem. 100, 9738-9758 (1996)

28. Tarver, C. M., Breithaupt, R. D., and Kury, J. W., J. Appl. Phys. 81, 7193-7202 (1997).

29. Sheffield, S. A., Engelke, R., Alcon, R. R., Gustavsen, R. L., Robbins, D. L., Stahl. D. B., Stacy, H. L. and Whitehead, M. C., Twelfth International Detonation Symposium, Office of Naval Research ONR 333-05-2, San Diego, CA, 2002, pp. 159-166.

30. Green, L. G. and James, E. Jr., Fourth Symposium (International) on Detonation, Office of Naval Research ACR-126, White Oak, MD, 1965, pp. 8691.

31. Gustavsen, R. L., Sheffield, S. A., and Alcon, R. R., Eleventh International Detonation Symposium, Office of Naval Research ONR 333005, Aspen, CO, 1998, pp. 821-827.

32. Campbell, A. W. and Engelke, R., Sixth Symposium (International) on Detonation, Office of Naval Research ACR-221, Coronado, CA, 1976, pp. 642-652.

33. Tarver, C. M., Kury, J. W., and Breithaupt, R. D., J. Appl. Phys. 82, 3771-3782 (1997).

34. Tarver, C. M. and McGuire, E. M., Twelfth International Detonation Symposium, Office of Naval Research ONR 333-05-2, San Diego, CA, 2002, pp. 641-649.

35 .Tarver, C. M., Propellants, Explosives, Pyrotechnics 30, 109-116 (2005).

36. Kury, J. W., Breithaupt, R. D., and Tarver, C. M., Shock Waves 9, 227-237 (1999).

37. Plaksin, I., Campos, J., Simoes, P., Portugul, A., Riberio, J., Mendes, R., and Gois, J., Twelfth International Detonation Symposium, Office of Naval Research ONR 333-05-2, San Diego, CA, 2002, pp. 650-658. 